\title{
Leiomyoma phosphoproteins involved in inhibition of oxidative stress and synthesis of reactive oxygen species
}

\author{
BLENDI URA ${ }^{1}$, LORENZO MONASTA ${ }^{1}$, GIORGIO ARRIGONI ${ }^{2,3}$, DANILO LICASTRO ${ }^{4}$, GIOVANNI DI LORENZO ${ }^{1}$, \\ FEDERICO ROMANO $^{1}$, BARTOLOMEA GAITA ${ }^{1}$, FEDERICA SCRIMIN $^{1}$ and GIUSEPPE RICCI ${ }^{1,5}$ \\ ${ }^{1}$ Institute for Maternal and Child Health-IRCCS ‘Burlo Garofolo', I-34137 Trieste; \\ ${ }^{2}$ Department of Biomedical Sciences, University of Padova, I-35121 Padova; ${ }^{3}$ Proteomics Center, University of Padova \\ and Azienda Ospedaliera di Padova, I-35129 Padova; ${ }^{4}$ Centro di Biomedicina Molecolare, Area Science Park; \\ ${ }^{5}$ Department of Medical, Surgery and Health Sciences, University of Trieste, I-34149 Trieste, Italy
}

Received July 15, 2019; Accepted September 13, 2019

DOI: $10.3892 /$ ijmm.2019.4377

\begin{abstract}
Uterine leiomyomas are benign smooth muscle cell tumors originating from the myometrium. The present study focused on leiomyoma and myometrium phosphoproteome enrichment by using immobilized metal affinity chromatography (IMAC). The phosphoproteome was analyzed by two-dimensional gel electrophoresis coupled with mass spectrometry. Western blotting was used for data validation. The results from IMAC identified 26 proteins significantly differentially phosphorylated in leiomyomas compared with normal myometrium. Three upregulated proteins (peroxiredoxin 2, protein disulfide isomerase family A member 3 and peroxiredoxin 4) were further validated by western blotting. Ingenuity pathway analysis revealed that four phosphoproteins were involved in the inhibition of oxidative stress and synthesis of reactive oxygen species. The present results demonstated for the first time an association between oxidative stress and phosphorylation in leiomyoma development.
\end{abstract}

\section{Introduction}

Uterine leiomyomas are benign smooth muscle cell tumors originating from the myometrium (1). During growth, a leiomyoma compresses the surrounding structures (the myometrium and connective tissue), causing the progressive formation of a sort of pseudocapsule, rich in collagen fibers (2), characterized by an abnormal extracellular matrix (ECM) and high interstitial fluid pressure (3). Several factors, such as

Correspondence to: Dr Blendi Ura, Institute for Maternal and Child Health-IRCCS 'Burlo Garofolo', 65/1 Via dell'Istria, I-34137 Trieste, Italy

E-mail: blendi.ura@burlo.trieste.it

Key words: leiomyoma, myometrium, oxidative stress, phosphoproteomics, two-dimensional gel electrophoresis, mass spectrometry growth factors, retinoic acid, ovarian hormones and vitamin D, are associated with tumor development $(4,5)$.

Protein phosphorylation is a common post-translational modification (6) and usually occurs in serine, threonine or tyrosine residues (7). In uterine leiomyomas, altered protein phosphorylation is associated with the inhibition of apoptosis and the promotion of cell survival (8). Several receptors, such as estrogen receptor $\alpha$ (9) and receptor tyrosine kinases (10), exhibit increased phosphorylation levels in leiomyoma compared with the myometrium, subsequently promoting tumor growth. Other receptors, such as transforing growth factor $\beta$, mediate gene expression via the phosphorylation of Smad proteins (11).

Oxidative stress is associated with several gynecological disorders, such as uterine fibroids and endometriosis (12). Fletcher et al (13) reported that leiomyoma is characterized by an impaired antioxidant cellular system, suggesting a role of oxidative stress in its pathogenesis. In tumors, the increase in reactive oxygen species (ROS) is balanced by the upregulation of antioxidant systems (14). Pyruvate dehydrogenase kinase 1 is a ROS sensor activated by the rise of oxidative stress, leading to detoxification and cell survival (15). Oxidative stress stimulates phosphorylation of mixed-lineage protein kinase 3 by ERK1/2, enhancing the invasion of cancer cells (16). Identification of changes in protein phosphorylation levels in leiomyoma associated with oxidative stress may be useful for the understanding of the physiopathology of the tumor.

The present study used immobilized metal affinity chromatography (IMAC), two-dimensional gel electrophoresis (2-DE) and mass spectrometry (MS) to analyze leiomyoma tissues. The aim was to identify differentially phosphorylated proteins involved in the suppression of oxidative stress and synthesis of ROS leading to tumor growth.

\section{Materials and methods}

Patients. Tissues samples were obtained from ten premenopausal patients who underwent hysterectomy for symptomatic uterine leiomyomas. All procedures conformed with the Declaration of Helsinki and were approved by 
the Review Board of the Institute for Maternal and Child Health-IRCCS 'Burlo Garofolo' (Trieste, Italy). All subjects involved signed a written informed consent. The median age of patients was 44 years, with a range of 36-48 years. The patients were recruited from January to Febuary 2019 at the Institute for Maternal and Child Health-IRCCS 'Burlo Garofolo' (Trieste, Italy), where all hysterectomies took place. Oncologic patients, HIV, HBV, HCV-seropositive patients, and patients with adenomyosis were excluded from the study. The patients had not received hormonal therapy in the three months prior to surgery.

Tissue samples. Two samples were collected from each patient: One from the central area of the leiomyoma and one from the unaffected myometrium. All leiomyomas were confirmed histologically as benign ordinary leiomyomas. Samples were stored at $-80^{\circ} \mathrm{C}$ until proteomic analysis was performed.

Phosphoprotein isolation and 2-DE. One hundred mg of myometrium and leiomyoma tissue from ten patients were used for phosphoprotein isolation using the Phosphoprotein Enrichment kit (Thermo Fisher Scientific, Inc.). Tissues were homogenized in buffer [1\% NP-40, $50 \mathrm{mM}$ Tris- $\mathrm{HCl}(\mathrm{pH} \mathrm{8.0)}$ ), $\mathrm{NaCl} 150 \mathrm{mM}$ ] with 1X Phosphatase Inhibitor Cocktail Set II (EMD Millipore), $2 \mathrm{mM}$ PMSF and $1 \mathrm{mM}$ benzamidine. The concentration of the supernatant was determined by Bradford assay. Tissue homogenates were then diluted to a final concetration of $0.5 \mathrm{mg} / \mathrm{ml}$ in lysis buffer provided by the Phosphoprotein Enrichment kit. Six ml of final samples were used for isolation of the phosphoproteins, according to the manufacturer's instructions.

For 2-DE analysis, a single patient-single gel strategy was adopted, and the analyzes were performed as previously described (17). For 2-DE analysis, $250 \mu \mathrm{g}$ of proteins from each sample were denatured in $315 \mu \mathrm{l}$ of dissolution buffer [7 M urea, $2 \mathrm{M}$ thiourea, 4\% 3-[(3-cholamidopropyl) dimethylammonio]-1-propanesulfonate, $40 \mathrm{mM}$ Tris, $65 \mathrm{mM}$ dithiothreitol (DTT) and 0.24\% Bio-Lyte 3/10 (Bio-Rad Laboratories, Inc.)] with a trace of bromophenol blue. ReadyStrip ${ }^{\mathrm{TM}} \mathrm{pH}$ 4-7 18-cm immobilized $\mathrm{pH}$ gradient (IPG) strips (Bio-Rad Laboratories, Inc.) were rehydrated in dissolution buffer at $50 \mathrm{~V}$ for $12 \mathrm{~h}$ at $20^{\circ} \mathrm{C}$, and isoelectric focusing (IEF) was performed in a PROTEAN IEF Cell (Bio-Rad Laboratories, Inc.). After the IEF, serial incubations were performed: first, the IPG strips were equilibrated for $15 \mathrm{~min}$ in an equilibration buffer [6 $\mathrm{M}$ urea, $2 \%$ SDS, $50 \mathrm{mM}$ Tris- $\mathrm{HCl}$ (pH 8.8), 30\% glycerol and 1\% DTT] and then in another equilibration buffer containing $4 \%$ iodoacetamide instead of DTT. For the second dimension, the equilibrated IPG strips were transferred to a $12 \%$ polyacrylamide gel.

After electrophoresis, gels were fixed in $40 \%$ methanol and $10 \%$ acetic acid for $1 \mathrm{~h}$, and then stained for $16 \mathrm{~h}$ with SYPRO Ruby (Bio-Rad Laboratories, Inc.). 2-DE gels were scanned with a Molecular Imager PharosFX System (Bio-Rad Laboratories, Inc.). Double experimental replicates were performed per sample. For all gels, molecular weights were determined by comparison with Precision Plus Protein Prestained Standards (Bio-Rad Laboratories, Inc.) covering a range $10-250 \mathrm{kDa}$, and analyzed using the Proteomweaver 4.0 software (Bio-Rad Laboratories, Inc.).
Western blotting. Phosphoprotein extracts $(20 \mu \mathrm{g})$ from IMAC columns used for 2-DE were separated by $12 \%$ SDS-PAGE and then transferred to a nitrocellulose membrane. The western blotting procedure for phosphoproteins was conducted as previously described (18). The membrane was blocked with $5 \%$ BSA in TBS $/ 0.05 \%$ Tween-20 (TBST) for $2 \mathrm{~h}$ at room temperature. After BSA saturation, the membrane was incubated overnight at $4^{\circ} \mathrm{C}$ with primary rabbit polyclonal antibodies against peroxiredoxin 2 (PRDX2; 1:800; cat. no. SAB2101878), protein disulfide isomerase family A member 3 (PDIA3; 1:400; cat. no. SAB2107799) and peroxiredoxin 4 (PDRX4; 1:500; cat. no. SAB4301759; all Sigma-Aldrich; Merck KGaA). The membrane was washed three times in TBST for $10 \mathrm{~min}$, and then incubated for $90 \mathrm{~min}$ at $4^{\circ} \mathrm{C}$ with a horseradish peroxidase-conjugated anti-rabbit immunoglobulin $\mathrm{G}$ antibody (1:3,000; cat. no. G4018; Sigma-Aldrich; Merck KGaA). Protein expression was visualized by chemiluminescence (SuperSignal West Pico Chemiluminescent Substrate; Thermo Fisher Scientific, Inc.), and the intensity of the signals was quantified by VersaDoc Imaging System (Bio-Rad Laboratories, Inc.). The intensities of the immunostained bands were normalized with the protein intensities measured with Red Ponceau (Bio-Rad, Laboratories, Inc.) from the same blot.

Trypsin digestion and MS analysis. Spots from 2-DE were digested and analyzed by MS, as described by Ura et al (19). After 2-DE gel excision, the spots were washed four times with $50 \mathrm{mM} \mathrm{NH}_{4} \mathrm{HCO}_{3}$ and acetonitrile (ACN; Sigma-Aldrich; Merck KGaA) alternatively, and dried under vacuum in a SpeedVac system. Three $\mu 1$ of $12.5 \mathrm{ng} / \mu 1$ sequencing grade modified trypsin (Promega Corporation) in $50 \mathrm{mM} \mathrm{NH}_{4} \mathrm{HCO}_{3}$ were added to gel spots for digestion (overnight at $37^{\circ} \mathrm{C}$ ). Peptide extraction was achieved by three changes of 50\% ACN/0.1\% formic acid (FA; Fluka). Peptide mixtures were dried under vacuum and dissolved in $10 \mu \mathrm{l}$ of $5 \% \mathrm{ACN} / 0.1 \%$ FA and $5 \mu \mathrm{l}$ of each sample were analyzed by liquid chromatography with tandem mass spectrometry (LC-MS/MS) on a 6520 Q-TOF mass spectrometer (Agilent Technologies, Inc.) coupled to a chip-based chromatographic interface.

Raw data files were converted into Mascot Generic Format (MGF) files with MassHunter Qualitative Analysis Software version B.03.01 (Agilent Technologies, Inc.) and searched with Mascot Search Engine (version 2.2.4; Matrix Science) through the Proteome Discoverer Software interface (version 1.4; Thermo Fisher Scientific, Inc.). Spectra were searched against the human section of the UniProt database (version July 2018, 95,057 sequences) using the following parameters: Enzyme specificity was set to trypsin with one missed cleavage allowed, while precursor and fragment ions tolerance were set to $20 \mathrm{ppm}$ and $0.05 \mathrm{Da}$, respectively. Carbamidomethyl cysteine and oxidation of methionine were set as fixed modification and variable modification, respectively. MS/MS spectra containing $<5$ peaks or with a total ion count $<50$ were discarded. Proteins were considered as positive hits if, for each protein, at least two unique peptides were identified with high confidence (FDR $<0.01 \%$ ). For protein spots that did not return any significant hit, a Peptide Mass Fingerprint (PMF) was also performed with Mascot. All identified proteins were verified to have phosphorylated residues in PhosphoSitePlus database (www.phosphosite.org). 
Table I. List of putative phosphoproteins with a significantly different abundance in leiomyoma compared with myometrium tissues.

\begin{tabular}{|c|c|c|c|c|c|}
\hline Accession number & $\begin{array}{c}\text { Spot } \\
\text { number }\end{array}$ & Protein description & $\begin{array}{c}\text { Gene } \\
\text { symbol }\end{array}$ & $\begin{array}{l}\text { Fold } \\
\text { change }\end{array}$ & Protein class \\
\hline A0A087WU08 & 7 & Haptoglobin & HP & 4.25 & Hydrolase \\
\hline P11021 & 17 & $78 \mathrm{kDa}$ glucose-regulated protein & HSPA5 & 3.61 & Chaperone \\
\hline H9KV75 & 19 & $\alpha$-actinin 1 & ACTN1 & 3.2 & $\begin{array}{l}\text { Cytoskeletal } \\
\text { protein }\end{array}$ \\
\hline A0A0C4DGB6 & 21 & Albumin & ALB & 3.1 & $\begin{array}{l}\text { Transfer/carrier } \\
\text { protein }\end{array}$ \\
\hline E9PFZ2 & 18 & Ceruloplasmin & $\mathrm{CP}$ & 3 & Oxidoreductase \\
\hline Q5JRR6 & 20 & Ubiquitin-like modifier-activating enzyme 1 & UBA1 & 3 & Ligase \\
\hline $\mathrm{H} 7 \mathrm{C} 3 \mathrm{~T} 4$ & 3 & Peroxiredoxin 4 & PRDX4 & 3 & Peroxidase \\
\hline Q3BDU5 & 8 & Prelamin A/C & LMNA & 3 & $\begin{array}{l}\text { Cytoskeletal } \\
\text { protein }\end{array}$ \\
\hline H7BZ94 & 26 & Protein disulfide-isomerase & $\mathrm{P} 4 \mathrm{HB}$ & 2.9 & Oxidoreductase \\
\hline P30101 & 11 & $\begin{array}{l}\text { Protein disulfide-isomerase family } \\
\text { A member } 3\end{array}$ & PDIA3 & 2.75 & $\begin{array}{l}\text { Disulfide } \\
\text { oxidoreductase }\end{array}$ \\
\hline P10809 & 25 & $60 \mathrm{kDa}$ heat shock protein & HSPD1 & 2.63 & Chaperone \\
\hline P18206-2 & 24 & Isoform 1 of vinculin & VCL & 2.54 & $\begin{array}{l}\text { Cytoskeletal } \\
\text { protein }\end{array}$ \\
\hline P02790 & 13 & Hemopexin & HPX & 2.45 & Metalloprotease \\
\hline P08238 & 16 & Heat shock protein HSP $90 \beta$ & HSP90AB1 & 2.32 & Chaperone \\
\hline P04792 & 3 & Heat shock protein $\beta 1$ & HSPB 1 & 2.3 & Chaperone \\
\hline E9PN50 & 9 & $26 \mathrm{~S}$ protease regulatory subunit $6 \mathrm{~A}$ & PSMC3 & 2.2 & Hydrolase \\
\hline Q8NBS9 & 10 & Thioredoxin domain-containing protein 5 & TXNDC5 & 2 & Isomerase \\
\hline P08603 & 22 & Complement factor $\mathrm{H}$ & $\mathrm{CFH}$ & 1.93 & $\begin{array}{l}\text { Complement } \\
\text { control protein }\end{array}$ \\
\hline P01023 & 23 & $\alpha 2$-macroglobulin & $\mathrm{A} 2 \mathrm{M}$ & 1.9 & $\begin{array}{l}\text { Defence } \\
\text { immunity protein }\end{array}$ \\
\hline B7ZAR1 & 14 & T-complex protein 1 subunit epsilon & CCT5 & 1.84 & Chaperone \\
\hline P28070 & 2 & Proteasome subunit $\beta$ type 4 & PSMB4 & 1.8 & $\begin{array}{l}\text { Defence } \\
\text { immunity protein }\end{array}$ \\
\hline Q13409-2 & 15 & $\begin{array}{l}\text { Isoform } 2 \mathrm{~B} \text { of Cytoplasmic dynein } \\
1 \text { intermediate chain } 2\end{array}$ & DYNC1H1 & 1.78 & $\begin{array}{l}\text { Cytoskeletal } \\
\text { protein }\end{array}$ \\
\hline P01023 & 19 & Peroxiredoxin 2 & PRDX2 & 1.7 & Oxidoreductase \\
\hline P01024 & 21 & Complement C3 & $\mathrm{CO} 3$ & 1.61 & $\begin{array}{l}\text { Complement } \\
\text { control protein }\end{array}$ \\
\hline Q16555 & 15 & Dihydropyrimidinase-related protein 2 & DPYSL2 & 1.5 & Metalloprotease \\
\hline P17661 & 5 & Desmin & DES & 0.07 & $\begin{array}{l}\text { Cytoskeletal } \\
\text { protein }\end{array}$ \\
\hline
\end{tabular}

Fold-change was defined as the ratio of the mean $\% \mathrm{~V}$ according to the formula: $\% \mathrm{~V}=\mathrm{V}$ single spot/V total spot of cases vs. controls (where $\mathrm{V}$ denotes the spot volume).

PANTHER and Ingenuity Pathway analyses. Phosphorylated proteins were analyzed by PANTHER 11.0 (Protein Analysis Through Evolutionary Relationships; http://www.pantherdb. org) and Gene Ontology (http://amigo.geneontology.org/rte). Proteins were then classified according to their protein class. Since the majority of the proteins identified were involved in multiple processes, only the most relevant ones were reported.
These proteins were analyzed by Ingenuity Pathway Analysis (IPA; Qiagen $\mathrm{GmbH}$ ), as previously described (20). Selected genes were used to generate bio-functions. For the filter summary, only high confidence associations (predicted) or that had been experimentally observed were considered.

Statistical analysis. Statistical analyses were performed with the non-parametric Wilcoxon signed-rank test for matched samples 

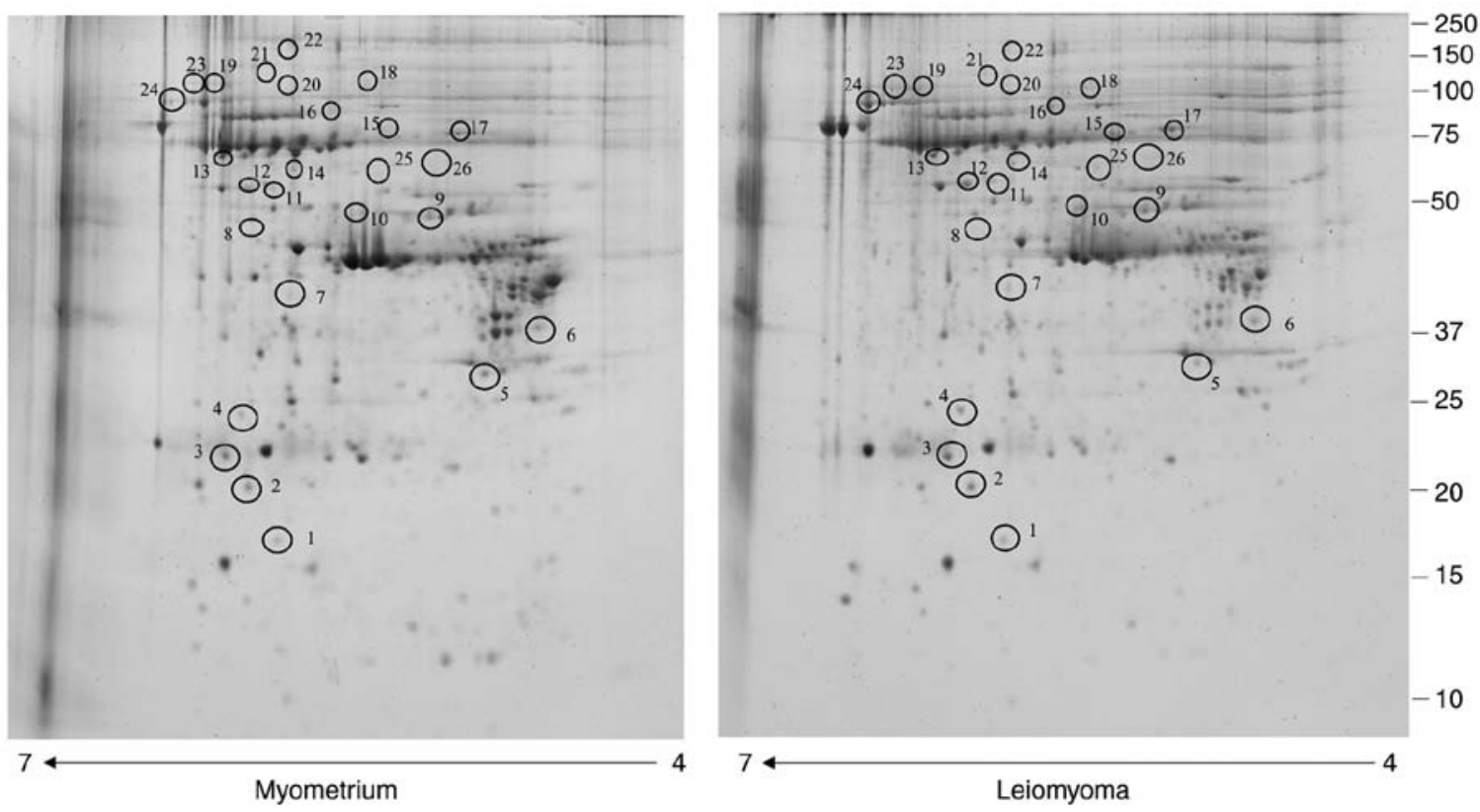

Figure 1. Two-dimensional electrophoresis map of normal myometrium and leiomyoma phosphoproteome enriched by immobilized metal affinity chromatography columns. Immobilized $\mathrm{pH}$ gradient 4-7 strips were used for the isoelectric focusing and 12\% polyacrylamide gel was used for the second dimension. The numbered circles indicate the differentially phosphorylated spots.

for both 2-DE and western blot data. $\mathrm{P}<0.05$ was considered to indicate a statistically significant difference. All analyses were conducted with Stata/IC 14.1 for Windows (StataCorp LLC).

\section{Results}

Enrichment by IMAC. For phosphoproteome enrichment, an IMAC column was used. This column, although non-specific, allowed us to efficiently enrich the phosphoproteome of both the leiomyoma and the myometrium tissues. An average of 1,800 spots were detected on gels for both types of the enriched phosphoproteome. The analysis revealed 26 protein spots (Table I) with a significantly different abundance (Fig. 1) in leiomyoma tissue compared with myometrium tissues. The correlation of gel-pairs performed well, with an average matching efficiency of $\sim 80 \%$. In the present study, only spots corresponding to putative phosphoproteins were considered, with the following criteria: fold change in $\% \mathrm{~V}$ (where $\mathrm{V}$ indicates the spot volume) $\geq 1.5$ or $\leq 0.6$ in intensity and $\mathrm{P}<0.05$. Of these spots, 25 were significantly upregulated $(>1.5$-fold $)$ while one was significantly downregulated $(<0.6$-fold).

Western blotting validation. Western blot analysis was used to confirm the alteration of three putative phosphorylated proteins: PRDX2, PDIA3 and PDRX4. The abundance of the propsphorylated forms of these proteins in five leiomyoma samples was compared to the matched normal myometrial tissue samples (same samples as used in 2-DE analysis) by western blotting (Fig. 2). The results demonsatrted that, in the five patients tested, phosphorylation levels of PRDX2, PDIA3 and PRDX4 were markedly higher in the leiomyoma tissues compared with the myometrium tissues, consistent with the 2-DE results.

Bioinformatic analysis. A PANTHER analysis of the identified proteins was conducted. Based on the PANTHER
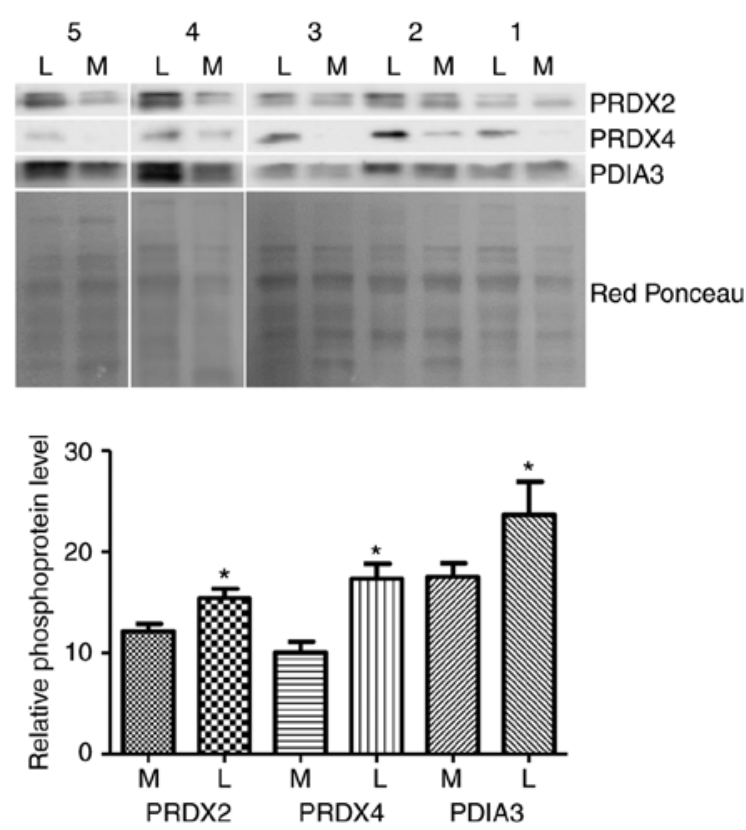

Figure 2. Western blot analysis was utilized to confirm the alteration in the phosphorylation of the proteins PRDX2, PDRX4 and PDIA3 in paired myometrium and leiomyoma tissues from five patients. The intensity of immunostained bands was normalized against the total protein intensities measured from the same blot stained with Red Ponceau. The bar graph shows the relative average expression (band density) of PRDX2, PDRX4 and PDIA3 in the myometrium and the leiomyoma. Data are presented as mean \pm standard deviation. ${ }^{*} \mathrm{P}<0.05$. PRDX, peroxiredoxin; PDIA3, protein disulfide isomerase family A member 3; L, leiomyoma; M, myometrium.

classification system, the results revealed that these proteins could be grouped into: Chaperone, enzyme modulator, transfer/carrier protein, cytoskeletal protein, signaling molecule and in three enzyme classes, hydrolase, ligase and oxidoreductase. 

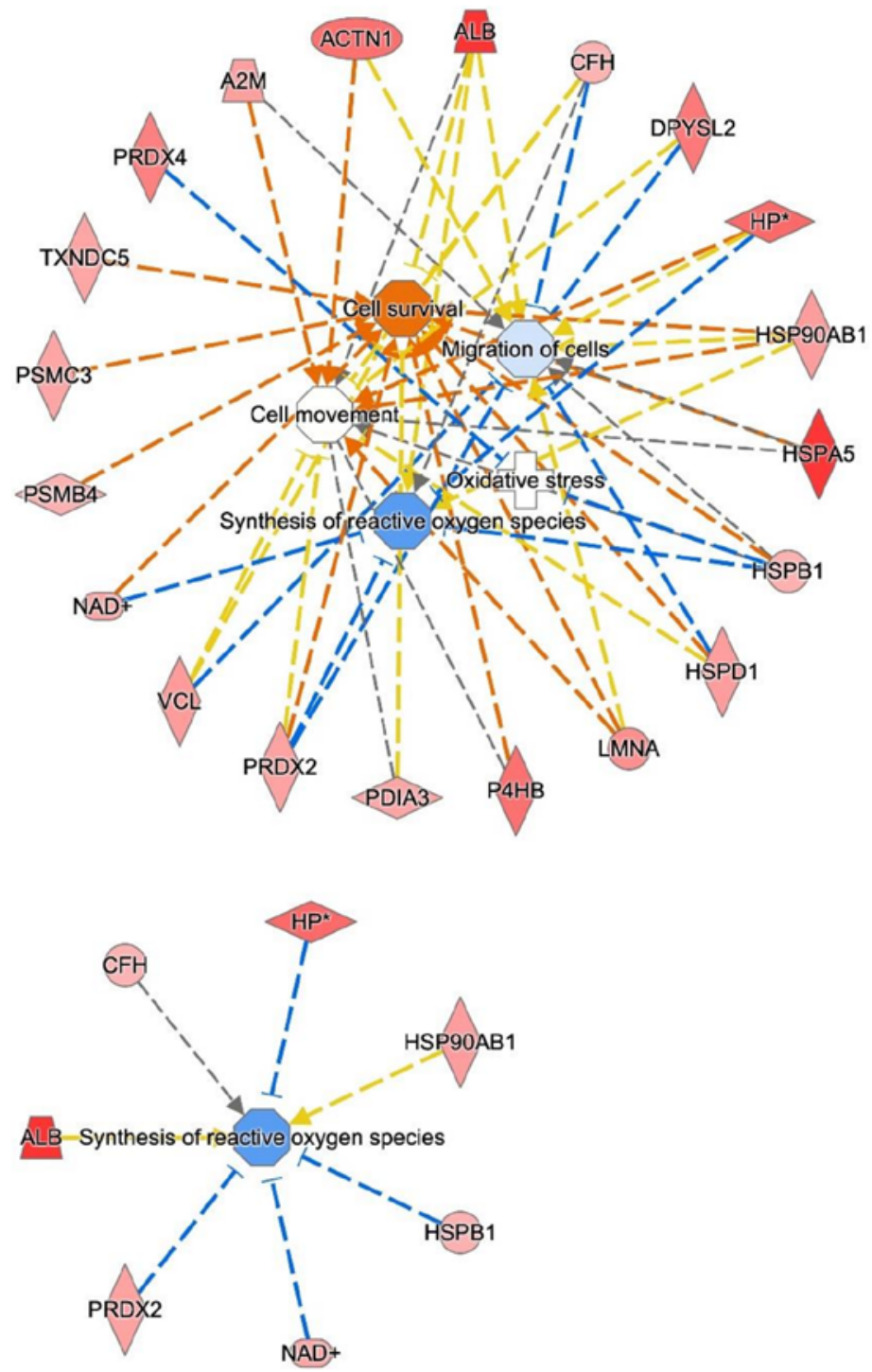
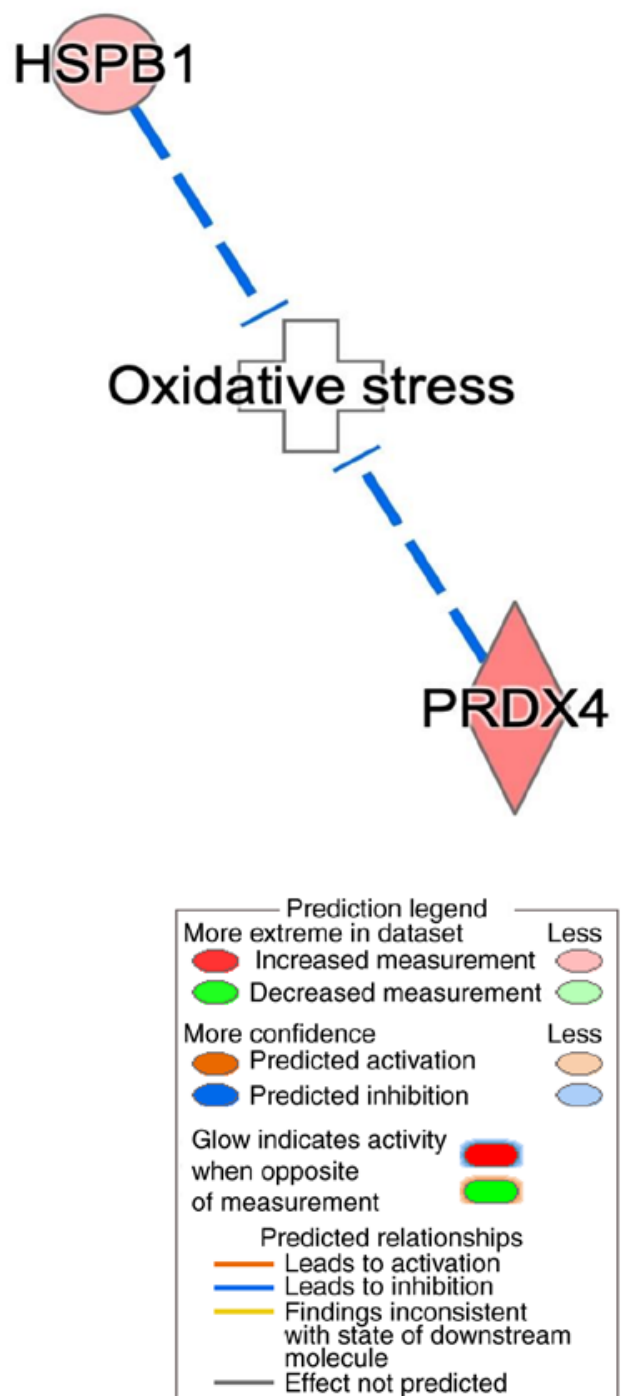

Figure 3. Network of significant biological functions involving the differentially phopshorylated proteins in leiomyoma. The functions of cell survival, migration of cells, cell movement, oxidative stress and synthesis of oxygen reactive species were found enriched by Ingenuity Pathway Analysis.

The in silico data analysis was then explanded by using the core analysis in the IPA software to construct a network in which these proteins were involved. The top networks in which these proteins were involved corresponded to: migration of cells, synthesis of ROS, cell movement, oxidative stress and cell proliferation of tumor cell lines (Fig. 3). Thirteen putative phosphoproteins were involved in the 'migration of cells' network, two were involved in the 'oxidative stress' network, five in the 'synthesis of ROS' network, 14 in the 'cell movement' network, while 13 were involved in the 'cell survival' network. Of these, four proteins [heat shock protein $\beta 1$ (HSPB1), PRDX4, haptoglobin (HP) and PRDX2] suppress oxidative stress and synthesis of reactive oxygen.

\section{Discussion}

Phosphorylation of membrane proteins and kinases is fundamental for leiomyoma development $(9,21)$. In the present study, by combining the IMAC column, 2-DE and MS, 26 putative phosphoproteins were identified to be differentially phosphorylated/expressed in leiomyoma tissues compared with myometrium tissues. By using western blotting, the differential levels of three putative phosphorylated proteins were confirmed: PRDX2, PDIA3 and PDRX4. All identified proteins have already been reported to be phosphorylated in vivo in the PhosphoSitePlus database, suggesting that the IMAC column was effective in isolating mainly phosphorylated proteins. Unfortunately, the validation experiments could not be performed using antibodies against the specific phosphorylated sites of these proteins, because these are not commercially available.

PRDX4 is a thiol-specific peroxidase that catalyzes the reduction of hydrogen peroxide. This enzyme protects against oxidative stress by detoxifying peroxides (22). The increase of this enzyme in tumors is associated with the protection of the cell from oxidative stress $(23,24)$.

HSPB1 is a heat shock protein which maintains denatured proteins in a folding-competent state (25). Phosphorylation of HSPB1 inhibits apoptosis by protecting the cell from oxidative stress (26). The present study identified this putative protein 
as differently phosphorylated in leiomyoma, suggesting a possible association of phosphorylated HSPB1 with the inhibition of oxidative stress and tumor growth.

PRDX2 is a thiol-specific peroxidase that serves a role in cell protection against oxidative stress by detoxifying peroxides, and as a sensor of hydrogen peroxide-mediated signaling events (27). This enzyme has an important role in cell survival by modulating the signaling involved in apoptosis and the phosphorylation of JNK, and by blocking the synthesis of ROS (28).

HP binds free hemoglobin $(\mathrm{Hb})$, prevents oxidative stress and acts as a potent immunoreactive modulator in the acute phase (29). Fedorovych et al (30) found that the function of the $\mathrm{HP} / \mathrm{Hb}$ complex in sera of patients with lung cancer was to neutralize superoxidative products (30). A similar mechanism may also be present in leiomyoma, in which the upregulation of phosphorylated HP may contribute to cell protection from reactive oxygen species.

In conclusion, the present study identified several putative phosphoproteins involved in oxidative stress in leiomyoma tissues. Further studies are needed to understand the role of phosphorylation in oxidative stress. The current data represented a step forward in the understanding of the mechanism involving oxidative stress in tumor growth.

\section{Acknowledgements}

We greatly appreciate the help of the obstetrics and gynecologigy operating room personnel of the Institute for Maternal and Child Health-IRCCS 'Burlo Garofolo'.

\section{Funding}

The work was funded with current research funds (grant no. 27/17) from our institute (Institute for Maternal and Child Health-IRCCS ‘Burlo Garofolo', Trieste, Italy).

\section{Availability of data and materials}

The datasets generated and analyzed during the current study are not publicly available due to restrictions imposed by the Regional Bioethics Committee of Friuli-Venezia Giulia (Comitato Etico Unico Regionale), but can be available from the corresponding author prior to approval of the research protocol by the Review Board of the Institute for Maternal and Child Health-IRCCS 'Burlo Garofolo' (Trieste, Italy).

\section{Authors' contributions}

Conceived and designed the experiments: GR and FS. Performed the experiments: BU, GA, BG and DL. Analyzed the data: LM, BU and GA. Contributed to data analysis: GDL and FR. Wrote the paper: GDL, FR, BU, LM and GA. All authors read and approved the final manuscript.

\section{Ethics approval and consent to participate}

Procedures incolving the use of human tissue were approved by the Review Board of the Institute for Maternal and Child
Health-IRCCS ‘Burlo Garofolo' (Trieste, Italy). All subjects involved signed a written informed consent.

\section{Patient consent for publication}

Not applicable.

\section{Competing interests}

The authors declare that they have no competing interests.

\section{References}

1. Ura B, Scrimin F, Arrigoni G, Aloisio M, Monasta L and Ricci G: Dysregulated chaperones associated with cell proliferation and negative apoptosis regulation in the uterine leiomyoma. Oncol Lett 15: 8005-8010, 2018.

2. Okolo S: Incidence, aetiology and epidemiology of uterine fibroids. Best Pract Res Clin Obstet Gynaecol 22: 571-588, 2008.

3. Ura B, Di Lorenzo G, Romano F, Monasta L, Mirenda G, Scrimin F and Ricci G: Interstitial fluid in gynecologic tumors and its possible application in the clinical practice. Int J Mol Sci 19, 2018.

4. Moravek MB, Yin P, Ono M, Coon JS V, Dyson MT, Navarro A, Marsh EE, Chakravarti D, Kim JJ, Wei JJ and Bulun SE: Ovarian steroids, stem cells and uterine leiomyoma: Therapeutic implications. Hum Reprod Update 21: 1-12, 2015.

5. Ura B, Scrimin F, Monasta L, Radillo O and Ricci G: Association between up-regulated expression proteins and circulating steroidal hormones in leiomyoma. Med Hypotheses 85: 515, 2015.

6. Ardito F, Giuliani M, Perrone D, Troiano G and Lo Muzio L: The crucial role of protein phosphorylation in cell signaling and its use as targeted therapy (Review). Int J Mol Med 40: 271-280, 2017.

7. Nishi H, Shaytan A and Panchenko AR: Physicochemical mechanisms of protein regulation by phosphorylation. Front Genet 5: 270, 2014.

8. Ura B, Monasta L, Arrigoni G, Battisti I, Licastro D, Di Lorenzo G, Romano F, Aloisio M, Peterlunger I, Stabile G, et al: Phosphoproteins involved in the inhibition of apoptosis and in cell survival in the leiomyoma. J Clin Med 8, 2019.

9. Kovács KA, Oszter A, Göcze PM, Környei JL and Szabó I: Comparative analysis of cyclin D1 and oestrogen receptor (alpha and beta) levels in human leiomyoma and adjacent myometrium. Mol Hum Reprod 7: 1085-1091, 2001.

10. Yu L, Saile K, Swartz CD, He H, Zheng X, Kissling GE, Di X, Lucas S, Robboy SJ and Dixon D: Differential expression of receptor tyrosine kinases (RTKs) and IGF-I pathway activation in human uterine leiomyomas. Mol Med 14: 264-275, 2008.

11. Chegini N, Luo X, Ding L and Ripley D: The expression of Smads and transforming growth factor beta receptors in leiomyoma and myometrium and the effect of gonadotropin releasing hormone analogue therapy. Mol Cell Endocrinol 209: 9-16, 2003.

12. Fletcher NM, Abusamaan MS, Memaj I, Saed MG, Al-Hendy A, Diamond MP and Saed GM: Oxidative stress: A key regulator of leiomyoma cell survival. Fertil Steril 107: 1387.e1-1394.e1, 2017.

13. Fletcher NM, Saed MG, Abu-Soud HM, Al-Hendy A, Diamond MP and Saed GM: Uterine fibroids are characterized by an impaired antioxidant cellular system: Potential role of hypoxia in the pathophysiology of uterine fibroids. J Assist Reprod Genet 30: 969-974, 2013.

14. Storz P: KRas, ROS and the initiation of pancreatic cancer. Small GTPases 8: 38-42, 2017.

15. Storz $\mathrm{P}$ and Toker A: Protein kinase $\mathrm{D}$ mediates a stress-induced NF-kappaB activation and survival pathway. EMBO J 22: 109-120, 2003.

16. Schroyer AL, Stimes NW, Abi Saab WF and Chadee DN: MLK3 phosphorylation by ERK1/2 is required for oxidative stress-induced invasion of colorectal cancer cells. Oncogene 37: 1031-1040, 2018.

17. Carcoforo P, Ura B, Mischiati C, Squerzanti M, Lanzara V, Cervellati C, Calza R, De Laureto PP, Frare E, Portinari M, et al: Comparative proteomic analysis of ductal breast carcinoma demonstrates an altered expression of chaperonins and cytoskeletal proteins. Mol Med Rep 7: 1700-1704, 2013. 
18. Ura B, Monasta L, Arrigoni G, Franchin C, Radillo O, Peterlunger I, Ricci G and Scrimin F: A proteomic approach for the identification of biomarkers in endometrial cancer uterine aspirate. Oncotarget 8: 109536-109545, 2017.

19. Ura B, Scrimin F, Arrigoni G, Athanasakis E, Aloisio M, Monasta L and Ricci G: Abnormal expression of leiomyoma cytoskeletal proteins involved in cell migration. Oncol Rep 35: 3094-3100, 2016.

20. Ura B, Scrimin F, Franchin C, Arrigoni G, Licastro D, Monasta L and Ricci G: Identification of proteins with different abundance associated with cell migration and proliferation in leiomyoma interstitial fluid by proteomics. Oncol Lett 13: 3912-3920, 2017.

21. Lemmon MA and Schlessinger J: Cell signaling by receptor tyrosine kinases. Cell 141: 1117-1134, 2010.

22. Basu A, Banerjee H, Rojas H, Martinez SR, Roy S, Jia Z, Lilly MB, De León M and Casiano CA: Differential expression of peroxiredoxins in prostate cancer: Consistent upregulation of PRDX3 and PRDX4. Prostate 71: 755-765, 2011.

23. Jiang H, Wu L, Mishra M, Chawsheen HA and Wei Q: Expression of peroxiredoxin 1 and 4 promotes human lung cancer malignancy. Am J Cancer Res 4: 445-460, 2014.

24. Yi N, Xiao MB, Ni WK, Jiang F, Lu CH and Ni RZ: High expression of peroxiredoxin 4 affects the survival time of colorectal cancer patients, but is not an independent unfavorable prognostic factor. Mol Clin Oncol 2: 767-772, 2014.
25. Rogalla T, Ehrnsperger M, Preville X, Kotlyarov A, Lutsch G, Ducasse C, Paul C, Wieske M, Arrigo AP, Buchner J and Gaestel M: Regulation of Hsp27 oligomerization, chaperone function, and protective activity against oxidative stress/tumor necrosis factor alpha by phosphorylation. J Biol Chem 274: 18947-18956, 1999.

26. Garrido C, Brunet M, Didelot C, Zermati Y, Schmitt E and Kroemer G: Heat shock proteins 27 and 70: Anti-apoptotic proteins with tumorigenic properties. Cell Cycle 5: 2592-2601, 2006.

27. Kamariah N, Sek MF, Eisenhaber B, Eisenhaber F and Grüber G: Transition steps in peroxide reduction and a molecular switch for peroxide robustness of prokaryotic peroxiredoxins. Sci Rep 6: 37610, 2016.

28. Kwon T, Rho JK, Lee JC, Park YH, Shin HJ, Cho S, Kang YK, Kim BY, Yoon DY and Yu DY: An important role for peroxiredoxin II in survival of A549 lung cancer cells resistant to gefitinib. Exp Mol Med 47: e165, 2015.

29. Abdullah M, Schultz H, Kähler D, Branscheid D, Dalhoff K, Zabel P, Vollmer E and Goldmann T: Expression of the acute phase protein haptoglobin in human lung cancer and tumor-free lung tissues. Pathol Res Pract 205: 639-647, 2009.

30. Fedorovych IP, Tymochko MF, Fedevych IuM, Fetsich TG and Korobov VM: Serum haptoglobin in lung cancer patients. Ukr Biokhim Zh (1978) 67: 103-105, 1995 (In Ukrainian). 